\title{
O Reino de Deus pregado nas cidades: uma análise a partir de Lucas $4,42-44$
}

\author{
The Kingdom of God preached in the cities: an analysis \\ from Luke 4,42-44
}

FABRIZIO ZANDONADI CATENASSI ${ }^{a}$

ILDO PERONDI (iD b

\section{Resumo}

O Jesus que Lucas apresenta em seu Evangelho é aquele que caminha e se desloca por cidades anunciando a boa notícia do Reino de Deus. Sua palavra é acompanhada de grandes sinais, mostrando sua autoridade ao tornar real o projeto que havia sido proclamado na sinagoga de Nazaré. O objetivo deste artigo é uma análise teológica do anúncio do Reino nas cidades no Evangelho de Lucas, partindo da análise de Lc 4,42-44. Com isso, é possível identificar os traços da missão de Jesus que se manifestam em seu anúncio: "Também para outras cidades é necessário que eu anuncie o Reino de Deus, porque para isso fui enviado" $(4,43)$. Para Lucas, Jerusalém é a cidade central na história salvífica, a cidade dos eventos pascais e da revelação do senhorio do Ressuscitado. Todo o Evangelho converge para Jerusalém e é dessa cidade que a mensagem parte em direção aos confins do mundo. Dessa forma, o Evangelho de Lucas ilumina a proposta do Papa Francisco, que quer uma Igreja "em saída".

Palavras-chave: Cidade. Evangelho de Lucas. Reino de Deus. Caminho.

\section{Abstract}

\footnotetext{
a Pontifícia Universidade Católica do Paraná (PUCPR), Londrina, PR, Brasil, Doutor em Teologia (PUCPR), e-mail: fabriziocatenassi@gmail.com

b Pontifícia Universidade Católica do Paraná (PUCPR), Curitiba, PR, Doutor em Teologia (PUCRio), e-mail: ildoper@gmail.com
} 
The Jesus presented by Luke in his Gospel is the one who walks and moves through cities announcing the good news of the Kingdom of God. His word is accompanied by great signs, showing his authority when makes real the project that had been proclaimed in the synagogue of Nazareth. The objective of this article is a theological analysis of the proclamation of the Kingdom in cities in the Gospel of Luke, starting from the analysis of Lk 4,42-44. With this, it is possible to identify the traces of Jesus' mission that are manifested in his proclamation: "It is also necessary for me to announce the Kingdom of God in other cities, because for this I was sent" $(4,43)$. For Luke, Jerusalem is the central city in salvific history, the city of Easter events and the revelation of the lordship of the Resurrected. The whole Gospel converges to Jerusalem, and it is from this city that the message departs towards the confines of the world. In this way, the Gospel of Luke illuminates the proposal of Pope Francis, who wants a Church "which goes forth".

Keywords: City. Gospel of Luke. Kingdom of God. Way.

\section{Introdução}

No Evangelho de Lucas, Jesus é um caminhante e sua mensagem é anunciada pelos caminhos da vida. O sagrado se manifesta não apenas nos santuários (o Templo de Jerusalém e as sinagogas), mas no chão da existência cotidiana, onde a vida se desenvolve em suas diferentes expressões. A vida e a pregação de Jesus recuperam o agir histórico de Deus, que caminhava com seu povo sem a necessidade de um único santuário fixo, andando de acampamento em acampamento (2Sm 7,4-7).

Um exemplo de como Jesus agia e anunciava o seu projeto do Reino de Deus é a perícope de Lc 4,42-44, que será o objeto desta pesquisa. Nela, Jesus manifesta sua liberdade diante dos desejos da multidão e mostra a exigência de deslocar-se por povoados e cidades, indo ao encontro das pessoas. 0 Evangelho de Lucas insiste no fato de que o Evangelho é anunciado por Jesus e pelos seus seguidores e seguidoras em centros urbanos, de forma que 0 estudo de como Lucas representa essas realidades ajuda a compreender os princípios que regem o agir de Jesus em relação a elas, bem como sua própria missão.

Em Lucas, Jesus caminha pelas cidades, nelas realiza milagres, para as cidades envia os setenta e dois discípulos a elas $(10,1)$, e é delas que as pessoas e multidões vêm à sua procura $(8,4)$. As cidades tornam-se locais prediletos 
para o anúncio do Evangelho. Loraschi (2007) nota que, em Lucas, um leproso é curado na cidade, o que é estranho, já que sua condição de enfermidade o impedia de entrar nos centros urbanos.

Diante disso, o objetivo deste artigo é uma análise teológica do anúncio do Reino nas cidades no Evangelho de Lucas, partindo da análise de Lc 4,4244. Com isso, é possível identificar os traços da missão de Jesus que se manifesta em seu anúncio, presente em todo o Evangelho de Lucas, seja no anúncio do Reino de Deus na Galileia, na caminhada a Jerusalém e também na cidade de Jerusalém: "Também para outras cidades é necessário que eu anuncie o Reino de Deus, porque para isso fui enviado" $(4,43)$.

\section{Análise de Lc 4,42-44}

\section{Contexto literário: a palavra e as ações que revelam o Reino}

A grande seção que vai de 4,14-9,50 mostra o ministério de Jesus na Galileia. O texto é aberto com a rejeição de Jesus em Nazaré (4,16-30), uma passagem com um papel programático para a sequência da narração (CATENASSI; PERONDI, 2019). Ali, na sinagoga, Jesus prega e ensina sobre sua natureza e missão, porém é perseguido e expulso da cidade. Uma notação final indica que Jesus prosseguiu (eporéueto, v. 30) com sua jornada.

Saindo dali, Jesus foi a Cafarnaum, de forma que sua palavra não se deteve com a perseguição e rejeição de Nazaré, mas fez caminho. Na época, essa nova localidade representava uma importante cidade para a região pois certamente reunia muitos viajantes e comerciantes, uma vez que lá passava a rota que conectava os portos do Mediterrâneo a Damasco, na Síria. Novamente, Lucas demarca que Jesus ensina e que sua palavra vai ao encontro do povo. É nas reuniões dos galileus que Jesus os encontra: na reunião litúrgica da sinagoga, na reunião afetiva na casa de Pedro e na reunião social, à porta da cidade.

Em contraste com o fracasso anterior, em Cafarnaum sua palavra é acompanhada de grandes sinais, mostrando autoridade ao tornar real o que havia sido proclamado em Nazaré. O efeito da pregação é a vitória sobre o mal, 
manifesta nas curas e exorcismos. O evangelista quer mostrar um ponto fundamental de seu ensinamento: a palavra pregada por Jesus é eficaz, vence as forças mortais e o que escraviza o ser humano na raiz (FABRIS, 2006).

Vemos nesses inícios do ministério de Jesus como é importante para a teologia lucana revelar a força da palavra de Jesus. O termo grego correspondente, lógos, aparece duas vezes no exorcismo na sinagoga $(4,32.36)$. Na cura da sogra de Simão (v. 39), a conjuração é conectada ao gesto de inclinar-se - uma mudança importante em relação a Mc 1,30 - de forma que palavra e ação vão sendo intimamente interligadas. No chamado dos primeiros discípulos ( $L C$ 5,1-11), a palavra de Jesus é o grande leitmotif que guia a narração, e que mostra sua força capaz de transformar o destino de toda uma vida (PERONDI; CATENASSI, SILVA, 2013). Como veremos a seguir, o texto de LC 4,42-44 mostra o impacto da palavra de Jesus pregada em Cafarnaum e os riscos que isso traz para seu ministério.

\section{Tradução e delimitação}

Apresentamos a tradução de Lc 4,42-44, seguindo o texto grego de Nestle et al. (2012), pelo princípio da correspondência formal. A segmentação é indicada com as letras sobrescritas:

v. 42 aE sendo dia, bsaindo, ' ${ }^{\text {C }}$ foi para um lugar deserto; ${ }^{\mathrm{d}}$ mas as multidões o buscavam, e e indo até ele ftentavam retê-lo, ${ }^{\text {ga }}$ fim de que não se afastasse deles.

v. 43 aPorém, ele lhes disse: "“'Também para outras cidades é necessário "que eu anuncie o Reino de Deus, "porque para isso fui enviado".

v. 44 aE foi proclamando nas sinagogas da Judeia.

O texto configura a última cena de uma sequência de eventos em Cafarnaum, conectados por indicadores geográficos (4,31.33.38.42) e cronológicos (4,31.40.42), como nota Green (1997). A cena é colocada após um dos típicos sumários lucanos (4,40-41) e se inicia no v. 42 com uma mudança de cenário (o lugar deserto) e uma nova classificação de personagens (as multidões). 
Após a exposição do cenário, com Jesus retirado, o conflito principal é apresentado: as multidões o encontram e querem retê-lo ( $v$.42bc). A resolução se dá com a fala de Jesus, que projeta sua evangelização para outras cidades (v. 43), sendo concluída pelo narrador com a constatação que isso se cumpriu (v. 44). A partir daqui, usando o típico egéneto que marca o começo de narrativas $(5,1)$, abre-se uma nova perícope com a apresentação de outra trama na região do lago de Genesaré, além de novos personagens. Quanto às fontes, Lucas parte fundamentalmente da narrativa marcana, mas as pequenas adaptações do texto revelam profundamente sua teologia, motivo pelo qual serão destacadas no comentário exegético-teológico.

\section{Comentário exegético-teológico}

Jesus se retira (v. 42a-c)

No Evangelho de Marcos, após seu primeiro dia de evangelização, Jesus se levanta e sai quando ainda estava escuro até ser encontrado por Simão, orando (Mc 1,35). Lucas altera esses elementos que denotam certa pressa de Jesus para que o vejamos iluminado pela luz do dia buscando retirar-se; não é como se ele quisesse fugir de algo (BOVON, 2005). Após uma grande obra salvífica ter sido manifesta pela palavra de Jesus $(4,14-30)$ e pelos milagres que acompanham a palavra (4,31-41), era de se esperar que Lucas mantivesse a atitude orante de Jesus, como acontece em muitos outros lugares do Evangelho $(3,21 ; 5,16 ; 6,12 ; 9,18.28 ; 10,21 ; 11,1 ; 22,32 ; 22,41 ; 23,46)$. Contudo, a informação é omitida. Por quê?

Ao deixar de lado a oração, a atenção do leitor recai sobre o deserto. $\mathrm{Na}$ lógica narrativa, pode-se recordar do lugar já citado como ambiente da tentação (4,1-13) (CRADDOCK, 1990). Nele, Jesus passará por mais um crisol de sua missão, sendo tentado pelos elogios das multidões. Ao mesmo tempo, ao não retratar a imagem de uma oração solitária de Jesus, parece que o relato ganha o dinamismo do Evangelho: Jesus segue seu caminho de maneira determinada, de forma que nenhuma tentação é capaz de detê-lo em sua missão. 
A ação da multidão: reter Jesus (v. 42c-f)

O cenário da rejeição em Nazaré ficou para trás. Agora, são multidões que procuram Jesus e vão até (héos, v. 42c) ele. Lucas mostra a ânsia do povo na busca por Jesus e para ouvir sua palavra (LC 5,1.19; 6,19 8,19.40; 12,1; 15,1; 21,38), como indica o uso incomum de héos, que não é classicamente usado para pessoas, mas para tempo ou lugar (PLUMMER, 1981). Ou seja, Jesus é retratado como um lugar de abrigo para a numerosa multidão.

Em Marcos, o acúmulo das curas milagrosas e da vitória espetacular de Jesus sobre o mal leva a pensar que todos buscam Jesus enclausurando-o na imagem de um curandeiro (Mc 1,37). A obra lucana deixa clara a intenção das multidões: querem retê-lo. Bovon (2005) ensina que assim como buscam reter Paulo em Cesareia (At 21,8-14), a multidão não quer ficar sem seu pastor e o busca para que a proteja sem interrupções.

O texto lembra o pedido "permanece conosco" $(24,29)$ dos discípulos de Emaús. Também ali, Jesus se detém brevemente, mas logo desaparece, pois a palavra do caminho, o pão e a comunidade são a garantia de sua permanência. A ação das multidões em Cafarnaum se configura, assim, como uma nova tentação no deserto: o sucesso da evangelização na cidade depois do fracasso em Nazaré confundirá a missão de Jesus?

Resposta de Jesus: o Reino de Deus anunciado nas cidades (v. 43)

A resposta de Jesus não é uma repreensão, mas um ensino contra a tentativa de que um lugar ou comunidade monopolizem seu ministério. A missão tem que continuar e tem que se ampliar para mais cidades. Por isso, sua resposta se inicia com "Também para outras cidades..." (v. 43b), como um recurso estilístico para dar ênfase à expressão (PLUMMER, 1981).

Jesus não pode estar amarrado a uma única realidade, enclausurado e guiado pelas vantagens pessoais, pelo elogio das multidões ou pelo sucesso de seu ministério. Ainda que outras rejeições o aguardem, a palavra deve se estender a outras cidades. Em Marcos, Jesus convoca os discípulos a irem a outras komopóleis (Mc 1,38), mas Lucas muda esse termo para pólesin. Pode 
ser que esses dois vocábulos gregos representem traduções possíveis do aramaico mahoza, “cidade, empório, região" (FITZMYER, 1987). Ainda assim, Lucas prefere alterar a opção marcana, usada para indicar "aldeias", com o intuito de centralizar o anúncio nas cidades. Sua intenção é, além de estilística, teológica.

Nota-se a insistência de Lucas no termo cidade, que aparece 40 vezes em Lucas, contra 26 citações de Mateus e 8 de Marcos (ARTUSO, 2013). Com esse termo designa Nazaré $(4,29)$, Cafarnaum $(4,31)$ e Naim $(7,11)$; poucas vezes fala de "aldeia" (kómen, 5,17; 8,1; 9,6.52-56; 10,38; 13,22; 17,12; 24,13.28). É provável que a insistência em que o Reino de Deus deva ser proclamado particularmente nas cidades seja uma projeção da situação urbana do cristianismo da época de Lucas (BOVON, 2005), em sentido sociológico: nelas se concentra grande parte do povo que sofre com a realidade urbana, política e religiosa desenvolvida nas cidades de Israel. A salvação precisa fazer eco onde o povo sofrido está!

Sair de Cafarnaum, nesse sentido, constitui uma resposta fiel de Jesus à tentação de atar-se ao glamour da cidade. Enquanto Marcos mostra a ida às outras cidades como resultado da inciativa de Jesus (Mc 1,38), Lucas indica que isso é necessário (dêi, v. 43b), mostrando um segundo dever de Jesus. Assim como era necessário (dêi, 2,49) estar na casa de seu Pai, também é uma exigência de sua missão ir aos povos.

A narrativa sai da dimensão dos grandes feitos e retorna ao anúncio quando mostra que, no mundo urbano, é necessário proclamar o Reino de Deus. As cidades são convidadas a serem os primeiros ouvintes dessa proclamação em forma de boa-nova (euangelísastái, v.43c) que dá sentido salvífico às ações. Assim, a libertação temporal é uma "antecipação da libertação definitiva e plena, que arranca o homem do medo da morte" (FABRIS, 2006, p. 62).

Em Marcos há somente a menção à pregação, mas Lucas melhora o texto mostrando seu conteúdo: a boa-nova, que é o Reino. Pela primeira vez, aparece a expressão “Reino de Deus" em Lucas, importante e frequente $(6,20$ 7,28; 8,1.10 etc.). Proclamar o Reino é reafirmar o projeto de vida apresentado na sinagoga de Nazaré (4,18-19). Tanto ali, citando o texto de Isaías, quanto na caracterização da missão de Jesus nos vv. 43-44, aparecem euangelízo ("evangelizar, anunciar”), apostéllo (enviar) e kerýsso ("proclamar”). Assim, na 
resposta de Jesus, encontramos uma reafirmação dos fundamentos da missão de Jesus e seu compromisso com o projeto divino (GREEN, 1997). Bovon (2005) diz que Lucas não dá em nenhuma outra parte um resumo melhor da missão e da mensagem de Jesus: o "é necessário" da história da salvação, o envio com uma missão cristológica que acontece por meio da palavra libertadora, e o Reino de Deus como conteúdo da sua pregação.

\section{Desfecho: Jesus, pregador itinerante (v. 44)}

Após acompanharmos Jesus escapando dos holofotes do sucesso de sua missão, o narrador nos mostra sua atitude fundamental: a pregação de cidade em cidade - o uso do particípio presente em "proclamando" (kerýsson, v. 44a) indica que a ação se estendeu no tempo. Trata-se de uma conclusão para toda a seção, encerrando os relatos do ministério de Jesus na Galileia que iniciaram em 4,14. $O$ texto retrata Jesus pregando nas sinagogas da Judeia quando esperaríamos encontrar a Galileia, seguindo a lógica dos capítulos posteriores'. Contudo, para Lucas, “Judeia” pode significar todo o país dos judeus, a Palestina como um todo (Lc 1,5; 6,17; 7,17; 23,5; At 2,9; 10,37; $11,1.29 ; 26,20)^{2}$.

Em uma última alteração do texto marcano, Lucas suprime os exorcismos que concluíam o relato de base (Mc 1,39) e amplia nossa visão geográfica da missão. Brown (2004) fala de uma geografia teológica de Lucas, que coloca nossa atenção no retorno de Jesus à Galileia em 4,14, e nos faz acompanhá-lo partindo rumo a Jerusalém a partir de 9,51. Jesus já havia sido caracterizado como profeta, mestre, médico, exorcista, Filho enviado pelo Pai, Messias, mas é a primeira vez que é caracterizado como o pregador por

\footnotetext{
${ }^{1}$ Um corpo grande de manuscritos, como A D K $\Gamma \Delta \Theta \Psi f^{13}$ e outros, inserem Galilaias no lugar de Judeia. Trata-se de uma harmonização do texto com a narrativa lucana, de forma que a lectio dificilior seja preferível para reconstruir o texto original.

2 Lucas segue a fraseologia dos autores clássicos de sua época (PLUMMER, 1981). Alguns autores pensam que essa citação é um bom exemplo de como a geografia lucana desconhece a Palestina, ao ponto de situar Cafarnaum na Judeia (BROWN, 2004). No contexto do Evangelho, essa ideia se dissipa rapidamente. É muito mais provável que se apresente aqui uma geografia teológica, universalizando a ação de Jesus a todo o território dos israelitas, o "país dos judeus".
} 
excelência (FITZMYER, 1987), um pregador itinerante. Já não é mais o povo que tem que ir ao deserto e ao Templo para encontrar-se com Deus; a terra em que estão é o novo cenário onde se manifesta o Reino de Deus e sua salvação (PAGOLA, 2012).

\section{A pregação do Reino e a cidade no Evangelho de Lucas}

O estudo de LC 4,42-44 salientou a dimensão teológica que o termo cidade ganha na perícope e sua extensão no projeto literário lucano. A partir disso, discutimos nesta seção as principais cidades que aparecem no caminho itinerante de Jesus e sua ligação com a mensagem do Reino de Deus.

\section{Jesus nas cidades da Galileia e arredores}

Depois de vencer as tentações do diabo (4,1-13), Jesus retorna à Galileia e, em um dia de sábado, vai à sinagoga de Nazaré, a cidade onde viveu. Ali, ele anuncia o discurso inaugural do seu ministério, no qual apresenta seu projeto de vida e salvação (4,16-20). Porém, em Nazaré, não realiza nenhum milagre, sofre a rejeição, a qual interpreta a partir do que aconteceu com os profetas do Antigo Testamento que também não tiveram boa aceitação em sua pátria. Jesus inicia como um fracassado na cidade onde se criou, mas tem claro o seu projeto e não se abala diante das dificuldades ou dos aparentes insucessos. A clareza de sua missão o faz superar as adversidades e seguir adiante.

Como desenvolvido na análise de Lc 4,42-44, era necessário que Jesus se dirigisse a outras cidades (v. 43b), o que foi colocado em prática. Ele não se prende aos espaços de culto, a cidades e locais ou a grupos. O anúncio do Reino de Deus tem urgência, por isso se movimenta com plena liberdade. Durante a sua atividade na Galileia, Jesus vai às sinagogas da região (4,44; 6,6; 8,1); ensina onde se encontra (5,31; 6,17-49; 7,16-35; 7,40-50; 8,4-18; 9,1-6; 9,1827; 9,38-50); desloca-se por cidades e locais (5,12; 6,1; 7,1; 7,11; 9,10; 9,18); vai para lugares desertos e montanhas para orar ou descansar (5,16; 6,12; 9,12; $9,28)$; está no barco atravessando o mar $(8,22.26)$; vai a uma cidade fora do 
território de Israel $(8,26-40)$. Anuncia enquanto caminha $(8,43-48)$ e vai também ao encontro das pessoas onde quer que estejam: nas casas (5,17-20; $5,29 ; 7,36 ; 8,19 ; 8,51)$, nos locais de trabalho $(5,1-2 ; 5,27)$, enterrando seus mortos (7,11-17). Da mesma forma, nota-se uma convergência no mesmo sentido: as pessoas e multidões de todas as cidades também vêm à sua procura para ouvir a sua mensagem e para serem curadas dos seus males (5,1; 6,17-19; $8,4 ; 8,40 ; 9,11 ; 9,37)$.

Outra atividade priorizada por Jesus nessas localidades é o chamado, instituição e formação de discípulos para virem em seu seguimento $(5,4,11$; 6,14-16; 9,1-6; 9,10; 9,18-26; 9,43b-50). Nas cidades galilaicas, a figura masculina era predominante nas instâncias representativas e de governo e somente aos homens recaía a responsabilidade política e o destino do povo. Jesus apresenta uma novidade: ele possui um grupo de mulheres discípulas "assim como os Doze" $(8,2)$. Somente Lucas nomina ainda na Galileia algumas mulheres deste grupo: Maria, chamada Madalena, Joana e Susana $(8,3)$. Os mestres da época não admitiam mulheres como discípulas. Jesus acolhe, alarga, inclui. Estas mulheres seguem e servem a Jesus; elas exercem seu serviço (diakonéo). Este grupo será fiel até o fim. Elas estarão com Jesus no caminho do Calvário $(23,27)$, aos pés da cruz $(23,29.55)$ e na manhã da ressurreição (24,1.10.22).

Nessa nova imagem de cidade proposta por Jesus, as mulheres podem oferecer sua vida pelo Reino. Elas serviam a Jesus e aos Doze, isto é, à Igreja. $O$ texto de $L c$ 8,3 diz que serviam com seus recursos, mas naquela época as mulheres dificilmente possuíam bens ou dinheiro. Portanto, mais que disponibilizar riquezas materiais, elas serviam com seu jeito, suas possibilidades, com sua voz, seu serviço, etc... Se nas sinagogas as mulheres não tinham espaço, na Igreja nascente elas terão um papel importante ( $R m$ 16,1; At 1,14; 12,12; 16,13-15; 17,4.12.34, etc.).

A boa nova de Jesus é o Reino de Deus, centro e resumo da sua mensagem e das suas ações (Mc 1,15; Mt 4,23; Lc 4,43; 8,1 etc.). Embora Jesus nunca definisse claramente nos evangelhos o que é o Reino de Deus, ilustrando-o por meio de parábolas e metáforas, é certo que sua definição levava em conta a situação política e social em que se encontrava o povo. A 
Palestina era dominada pelos romanos, desde 63 a.C., que impunham uma opressão em todos os sentidos: politicamente, eram os romanos que governavam com o apoio dos saduceus; economicamente, o povo era explorado com altos impostos e taxas; socialmente, este projeto causava exclusão e marginalização, desemprego, fome e os pequenos proprietários perdiam suas terras; ideologicamente vivia-se sob a famigerada Pax Romana, que não era a paz e sim uma "paz" imposta à força e violência pelo poderoso exército romano; religiosamente, a interpretação legalista da Lei se tornava outra opressão e exclusão (PAGOLA, 2012). Sendo assim, o Reino de Deus pregado por Jesus é uma reviravolta em todos estes aspectos. É o fim da opressão, da dominação romana, da exploração econômica, política e religiosa. É a construção de uma sociedade justa, fraterna e igualitária que nasce e se enraíza no amoroso plano salvífico divino. O Reino se caracteriza como uma proposta que nasce de baixo para cima, começa pela Galileia e alcança a capital Jerusalém. É boa notícia para o povo, sobretudo para os pobres, e má notícia para os opressores.

A atividade de Jesus na Galileia é marcada pelo anúncio do seu projeto, instituição dos Doze e a sua manifestação como o Messias de Israel, anunciando, por meio de palavras e ações, a chegada do Reino de Deus. Jesus vai em busca das ovelhas perdidas e se compadece da sua situação, por isso age em seu favor. Nas cidades, Jesus "curou doentes, manifestando-se como o médico, o salvador, o rei, o filho de Deus. Agora empreende o caminho em direção a Jerusalém" (BOVON, 2002, p. 40, tradução nossa).

\section{A caminho de jerusalém}

O versículo 9,51 marca uma reviravolta dentro do Evangelho de Lucas: "Quando se completaram os dias de sua assunção, ele tomou resolutamente o caminho de Jerusalém". Jesus deixou a Galileia e, junto com sua comitiva, tomou o caminho em direção à grande cidade da Judeia. O relato lucano dessa caminhada ocupa mais da metade do seu Evangelho, diferente de Marcos (um capítulo apenas) e Mateus (dois capítulos). Essa jornada é uma boa oportunidade para passar por povoados e vilarejos enunciando a Boa nova do Reino de Deus. Ao mesmo tempo, o caminho é o lugar privilegiado de 
formação dos discípulos e discípulas, no qual eles podem observar a relação que Jesus estabelece com o povo das cidades, de maneira especial, os pobres do Evangelho (BRITO; ALMEIDA, 2019).

Jesus caminha em direção a Jerusalém porque lá deve acontecer a sua assunção $(9,51)$ e o seu "êxodo" (é sobre o seu "êxodo" que falam os três personagens da transfiguração em 9,31). A viagem toda é vivida no pressentimento da morte: "mas hoje e amanhã, devo prosseguir o meu caminho, pois não convém que um profeta pereça fora de Jerusalém" (13,33).

Outra constatação é que Lucas não nomina as cidades e locais por onde Jesus e a comitiva passam. A única exceção é para Jericó, mencionada duas vezes $(18,35 ; 19,1)$ (ERNST, 2000), já que, na história de Israel, é o lugar do cumprimento da promessa da terra feita aos patriarcas. Jericó prepara a realização do que foi anunciado, mas apontando para a cidade de Jerusalém, cuja centralidade na vida de Jesus vai dando o ritmo para o deslocamento: "Atravessava cidades e povoados, ensinando e encaminhando-se para Jerusalém" (13,22); "Como ele se encaminhasse para Jerusalém, passava através da Samaria e da Galileia" (17,11); "Eis que subimos a Jerusalém e lá se cumprirá tudo o que foi escrito pelos profetas" $(18,31)$; "Acrescentou uma parábola, porque estava perto de Jerusalém..." (19,11); "Caminhava à frente, subindo para Jerusalém" $(19,28)$.

Se Cafarnaum testemunha grandes feitos que revelam o Reino, as localidades visitadas no caminho têm uma experiência diferente. Com o rosto de Jesus transfigurado $(9,29)$ termina a "catequese da escuta" e começa a "catequese da visão"; o evangelho não é só palavra a ser escutada, mas também caminho a ser percorrido (FAUSTI, 2011). Poucos são os milagres realizados, apenas quatro (13,10-12; 14,1-6; 17, 11-19; 18,35-40), diferente da seção do anúncio na Galileia na qual Lucas narra 14 milagres.

Na longa caminhada até Jerusalém Jesus se dedica mais ao anúncio do Reino de Deus por onde passa e ao ensinamento sobre o seguimento que espera dos seus discípulos. Casalegno (2003) ressalta que os discípulos também fazem o seu êxodo. Com o verbo symporéuomai ("viajar com" ou "coviajar", 14,25), Lucas indica que os discípulos caminham com Jesus. Ele caminha à frente $(19,28)$ e os discípulos o seguem, porque entendem que ele é o guia em quem podem confiar.

Jesus se move com passos decididos e determinados como o Messias em direção à cidade que mata os profetas, como anunciou no oráculo sobre a 
cidade santa: "Jerusalém, Jerusalém, que matas os profetas e apedrejas os que te foram enviados!" $(13,34)$. Da mesma forma, Jesus chora sobre Jerusalém ao vê-la, porque não é capaz de reconhecer o tempo da visita de Deus (19,41, passagem que se encontra somente no Evangelho de Lucas). Nos dois primeiros anúncios da paixão (9,22 e 9,44-45), assim como o relato da transfiguração (9,28-36), Jesus já havia indicado que o caminho a Jerusalém o levaria à agonia e ao martírio, para se cumprir a profecia do Messias que sofre (At 26,23) (BOVON, 2002).

Mesmo que Jesus saiba o que o espera em Jerusalém, também é "necessário" (dêi) que vá para lá, conforme já havia anunciado: "é necessário que o Filho do Homem sofra muito, seja rejeitado pelos anciãos, chefes dos sacerdotes e escribas, seja morto e ressuscite ao terceiro dia" (9,22); "hoje e amanhã e depois de amanhã é necessário prosseguir o meu caminho" (13,33). E repetirá também em Jerusalém "mas é necessário primeiro que ele sofra muito e seja rejeitado por esta geração" (cf. 22,37; 24,7.26.44). A expressão "é necessário" é sempre colocada na boca de Jesus, por isso ela tem um valor forte dentro do Evangelho, pois "além de frisar a decisão irrevogável de Jesus ir para Jerusalém, indica a necessidade de ele se submeter ao plano de Deus que deve se cumprir em conformidade com a revelação do Antigo Testamento" (CASALEGNO, 2003, p. 134).

\section{O anúncio do Reino em Jerusalém}

Finalmente, Jesus está na maior cidade de Israel: Jerusalém. Mesmo que durante toda a caminhada houvesse uma tensão em relação a esta localidade, Lucas não dá muito destaque à entrada de Jesus na cidade. Sua primeira atividade é ir ao Templo, o que recebe uma ênfase particular ao representar o destino final da longa caminhada. "Jesus entra no Templo como o rei messiânico, como aquele que 'vem em nome do Senhor' e que dá a paz, conforme as aclamações do povo em sua entrada em Jerusalém (19,38)" (CASALEGNO, 2003, p. 167). Como todo peregrino, parece que seu desejo é fazer uma oração, no entanto, diante do que ele encontra, expulsa os vendilhões e, citando os profetas Isaías e Jeremias, denuncia que a casa de oração foi transformada num covil de ladrões (19,45-46).

Lucas estende o anúncio de Jesus em Jerusalém, de modo que sua pregação deve ter durado vários dias: "diariamente ensinava no Templo" 
$(19,47)$; "certo dia enquanto ensinava o povo no Templo" (20,1); "Durante o dia ensinava no Templo, mas passava as noites ao relento, no monte chamado das Oliveiras, E todo o povo madrugava junto com ele no Templo, para ouviIo" (21,37-38). Jesus agia como mestre que ensina e como o Messias esperado que anuncia boas novas ao povo $(20,1.45 ; 21,38)$. Seus ensinamentos agradavam o povo que o ouvia, e isso causou medo aos seus adversários $(20,19.26 ; 23,2)$.

$\mathrm{Na}$ cidade santa, Jesus também atuou como o profeta que denuncia os líderes religiosos e políticos. Anunciar o Reino de Deus é também denunciar a cidade, o Templo e aqueles que são responsáveis pela exploração, pelas dores e sofrimentos do povo. Seus adversários eram os chefes dos sacerdotes, anciãos, saduceus, escribas e fariseus, os quais constituíam as camadas altas da sociedade, pertencendo em sua maioria ao sinédrio (CASALEGNO, 2003). O conflito com escribas e fariseus era mais sobre questões morais; o enfrentamento com os dirigentes poderosos do Templo já era mais temível, pois "o anúncio da implantação eminente do Reino de Deus, sua visão crítica da situação, seu programa de solidariedade com os excluídos e sua liberdade representavam uma radical e perigosa alternativa ao sistema imposto por Roma" (PAGOLA, 2012, p. 410). Indispondo-se contra essas elites, por consequência, Jesus também teve como adversários os romanos, que dominavam a nação. A cidade que abrigava a história sagrada dos judeus havia se tornado palco dos mais diversos conflitos entre grupos e nações.

Os embates se davam através de discursos proféticos ou perguntas e respostas bem formuladas (20,3-8.21-25.27-40) e também por meio de parábolas (20,9-19). Como mestre habilidoso, Jesus conseguia calar a todos que questionavam de onde vinha a sua autoridade $(20,2)$ e se defendia dos chefes que contra ele enviavam espiões para surpreendê-lo em alguma armadilha, a fim de poderem entregá-lo ao poder romano $(20,20)$.

O cap. 21 inicia com a denúncia contra os ricos que queriam ser vistos e elogiados por suas doações ao Templo; em contrapartida, Jesus valoriza a oferta da pobre viúva (21,1-4). O restante do capítulo é dedicado a discursos que preanunciam a destruição da cidade de Jerusalém e seu Templo. Diante da eminente catástrofe, Jesus exorta o povo a manter-se sempre em vigilância. 
Jesus dedica os últimos momentos antes de ser preso aos preparativos para os acontecimentos, especialmente a celebração da Páscoa. Lucas dá a entender que a Páscoa é celebrada com todos os seus discípulos $(22,11)$ ou com os apóstolos $(22,14)$. Durante a ceia pascal, dá as últimas recomendações aos seus discípulos (22,21-38) e então se retira para o Monte das Oliveiras onde, em oração e angústia, prepara-se para a hora decisiva (22,39-46).

Sua prisão, condenação e morte na cruz não deixam de ser momentos de anúncio e denúncia por meio do testemunho. Jesus defende-se das acusações, passa das mãos do sinédrio para o poder romano até ser conduzido ao Calvário. A cidade de Jerusalém, que não quis receber o anúncio do Reino, é a cidade que levou Jesus à morte, a mesma cidade que mata os profetas, confirmando o oráculo de 13,34. Segundo Fausti “O amor morre porque não é amado. Mas a sua morte é capaz de fazer nascer liberdade e amor onde ainda existe escravidão e egoísmo" (2011, p. 658).

O silêncio da morte de Jesus é rompido pelos anúncios da sua ressurreição. Diferente de Marcos e Mateus, que remetem as aparições aos discípulos na Galileia, Lucas indica que é na cidade de Jerusalém que os discípulos devem permanecer para o encontro com o Ressuscitado. Os discípulos no caminho de Emaús dirigem-se para fora de Jerusalém, porém o que acontece no caminho e na casa, faz com que entendam que eles não devem abandonar a cidade e sim retornar a ela. É lá que acontece a aparição aos Doze e o envio missionário (24,36-49).

Essa centralidade de Jerusalém é marcante para Lucas porque ela é a cidade central na história salvífica, a cidade dos eventos pascais e da revelação do senhorio do Ressuscitado. De lá acontecerá a irradiação do Evangelho com movimento centrífugo em direção ao exterior (At 1,8), movimento inverso àquele centrípeto da longa caminhada a Jerusalém (9,51-19,44) (ERNST, 2000). No Evangelho tudo converge para Jerusalém; nos Atos, é da cidade de Jerusalém que a mensagem parte em direção aos confins do mundo.

\section{Considerações finais: até os confins do mundo!}

Lucas procurou mostrar em seu Evangelho um Jesus que está sempre a caminho, passando por cidades e povoados. Ele vai ao encontro das pessoas, 
onde quer que estejam, para anunciar-Ihes a boa notícia do Reino de Deus, seja na fase inicial na Galileia, na longa caminhada que ocupa mais da metade do seu Evangelho ou na cidade de Jerusalém e seu Templo.

O ambiente das cidades como objeto da evangelização é uma característica mais acentuada em Lucas do que nos outros evangelhos, e isso também sucederá em seu segundo livro, os Atos dos Apóstolos. O Evangelho é a caminhada de Jesus; os Atos são a caminhada da Igreja. Se no Evangelho tudo confluía para a cidade de Jerusalém, a partir da ressurreição de Jesus, tudo começa em Jerusalém e se desloca até os confins do mundo, os quais representam Roma. De fato, chegando a Roma, chegava-se ao mundo sobre o qual se estendia o império.

É consenso que At 1,8 preanuncia e antecipa todo o desenvolvimento do segundo volume lucano de Jerusalém aos confins do mundo. Jesus anuncia que em Jerusalém eles receberão uma força/energia (dýnamis), a do Espírito Santo, que desceria sobre os discípulos para serem testemunhas em Jerusalém (At 1,8), em toda a Judeia (At 8-12), na Samaria (At 8), e até os confins da terra. $O$ roteiro segue as narrativas das viagens de evangelização em Chipre, Ásia Menor, Macedônia e Acaia (At 13-14; 15-20), e segue a chegada de Paulo a Roma em At 28. As cidades e regiões novamente são os locais privilegiados para o anúncio.

Jerusalém torna-se, assim, a cidade onde os discípulos de Jesus amadurecem a sua compreensão da Páscoa; é a cidade da efusão do Espírito Santo no dia de Pentecostes e é a cidade de onde eles serão enviados em missão (literalmente, "testemunho") universal. Aquela Jerusalém é, então, a comunidade-mãe e a comunidade ideal (conforme a vida exemplar da comunidade em At 2,42-48; 4,32-37; 5,12-16), nascida da Páscoa e do Pentecostes.

A itinerância de Jesus é modelo da Igreja que deve sempre ser missionária, "em saída" como sonha o Papa Francisco, revelando o desejo de comunicar a alegria da boa notícia do Reino de Deus a todas as pessoas e lugares, como fez Jesus Cristo. Ele incentiva os evangelizadores a serem tomados da alegria que o Evangelho proporciona a levá-la às pessoas que sofrem, estão excluídas ou sedentas de ouvir a Palavra de Deus. O desejo de 
Francisco é que a Igreja saia das amarras na qual se encontra, presa às estruturas. Essa é a Igreja em saída que ele espera:

Saiamos, saiamos para oferecer a todos a vida de Jesus Cristo. Repito aqui, para toda a Igreja, aquilo que muitas vezes disse aos sacerdotes e aos leigos de Buenos Aires: prefiro uma Igreja acidentada, ferida e enlameada por ter saído pelas estradas, a uma Igreja enferma pelo fechamento e a comodidade de se agarrar às próprias seguranças (FRANCISCO, 2013, EG 49).

Francisco exorta os ministros do Evangelho para que não fiquem presos nos templos, em atitude passiva, mas se coloquem a caminho, anunciando através da palavra e do testemunho. Ele recomenda aos evangelizadores que sintam o "cheiro das ovelhas" e que estas escutem a sua voz (EG 24).

Neste período da Covid-19, Lucas ilumina a caminhada da Igreja que, diante dos templos fechados ou com público reduzido, é convidada a sair e ir pelas cidades e locais onde o povo de Deus se encontra para anunciar e testemunhar a boa notícia do Reino de Deus. É certo que o isolamento social impõe restrições, no entanto, novas formas de evangelização foram criadas para que a mensagem do Evangelho chegue até as casas. A pandemia ensina que o encontro com o Sagrado se dá também fora dos santuários, lá onde a vida se faz presente.

\section{Referências}

ARTUSO, V. O Evangelho de Lucas: introdução teológica na perspectiva da missão. Contemplação, Marília, n. 6, 2013. Disponível em: http://fajopa.com/contemplacao/index.php/contemplacao/article/view/39. Acesso em: 27 jun. 2021.

BOVON, F. El Evangelio según Lucas II: LC 9,51-14,35. Salamanca: Ediciones Sígueme, 2002. BOVON, F. El Evangelio según Lucas I: Lc 1,1-9,50. Salamanca: Ediciones Sígueme, 2005. BRITO, A. I. A.; ALMEIDA, B. A. B. O caminho dos discípulos em Lucas: caminho de fé e discernimento. Encontros Teológicos, Florianópolis, v. 34, n. 2, p. 361-380, 2019.

BROWN, R. E. Introdução ao Novo Testamento. São Paulo: Paulinas, 2004.

CASALEGNO, A. Lucas. A caminho com jesus Missionário. São Paulo: Loyola, 2003.

CATENASSI, F. Z.; PERONDI, I. Bíblia e ciência da linguagem: recursos literários e cenas-tipo no Evangelho de Lucas. Teoliterária, São Paulo, v. 9, n. 17, p. 337-358, 2019. 
CRADDOCK, F. B. Luke. Lousville: John Knox Press, 1990.

ERNST, J. II Vangelo secondo Luca I. Brescia: Morcelliana, 2000.

FABRIS, R. O Evangelho de Lucas. In: FABRIS, R.; MAGGIONI, B. Os Evangelhos II. 4. ed. São Paulo: Loyola, 2006. p. 9-248.

FAUSTI, S. Una comunità legge il vangelo di Luca. Bologna: EDB, 2011.

FITZMYER, J. A. El evangelio según Lucas II: traducción y comentario. Capítulos 1-8,21. Madrid: Cristiandad, 1987.

FRANCISCO. Exortação Apostólica Evangelli Gaudium (EG). São Paulo: Paulinas, 2013.

GREEN, J. B. The Gospel of Luke. Grand Rapids: Eerdmans, 1997.

LORASCHI, C. A espiritualidade no cotidiano a partir do Evangelho de Lucas. Encontros Teológicos, Florianópolis, v. 22, n. 2, p. 9-23, 2007.

NESTLE, E.; et al. Novum testamentum graece. 28. ed. Barueri, Sociedade Bíblica do Brasil; Stuttgart: Deutsche Biblegesellschaft, 2012.

PAGOLA, J. A. Jesus: aproximação histórica. 5. ed. Petrópolis: Vozes, 2012.

PERONDI, I.; CATENASSI, F. Z.; SILVA, G. S. A centralidade da Palavra de Deus em LC 5,1-11. Horizonte: Belo Horizonte, v. 11, n. 30, p. 682-708, abr./jun. 2013.

PLUMMER, A. A critical and exegetical commentary on the Gospel According to S. Luke. 3. ed. Edinburgh; T\&T Clark, 1981. 